\title{
Effect of setting high APRV guided by expiratory inflection point of pressure-volume curve on oxygen delivery in canine models of severe acute respiratory distress syndrome
}

\author{
JIA-QIONG LI ${ }^{1 *}$, HONG-YANG XU ${ }^{2 *}$, MAO-QIN LI ${ }^{3}$ and JING-YU CHEN ${ }^{4}$ \\ ${ }^{1}$ Department of Critical Care Medicine, Xuzhou Hospital Affiliated to Southeast University, Xuzhou Central Hospital, \\ Xuzhou, Jiangsu 221009; ${ }^{2}$ Department of Critical Care Medicine, Wuxi People's Hospital Affiliated to \\ Nanjing Medical University, Wuxi, Jiangsu 214002; ${ }^{3}$ Department of Critical Care Medicine, Xuzhou Hospital Affiliated to \\ Southeast University, Xuzhou Central Hospital, Xuzhou, Jiangsu 221009; ${ }^{4}$ Department of Lung Transplant Center, \\ Wuxi People's Hospital Affiliated to Nanjing Medical University, Wuxi, Jiangsu 214002, P.R. China
}

Received December 30, 2015; Accepted June 14, 2016

DOI: 10.3892/etm.2016.3456

\begin{abstract}
In the present study, the effect of setting high airway pressure release ventilation (APRV) pressure guided by an expiratory inflection point of pressure-volume (PV) curve following lung recruitment maneuver (RM) on oxygen delivery $\left(\mathrm{DO}_{2}\right)$ in canine models of severe acute respiratory distress syndrome (ARDS) was examined. Canine models of severe ARDS were established by intravenous injection of oleic acid. After injection of sedative muscle relaxants, a $\mathrm{PV}$ curve plotted using the super-syringe technique, and the pressure at lower inflection point (LIP) at the inhale branch and the pressure at the point of maximum curvature (PMC) at the exhale branch were measured. The ventilation mode was biphasic positive airway pressure (BiPAP), an inspiration to expiration ratio of 1:2, and $\mathrm{P}_{\text {high }} 40 \mathrm{~cm} \mathrm{H}_{2} \mathrm{O}, \mathrm{P}_{\text {low }} 25 \mathrm{~cm} \mathrm{H}_{2} \mathrm{O}$. $\mathrm{P}_{\text {high }}$ was decreased to $30 \mathrm{~cm} \mathrm{H}_{2} \mathrm{O}$ after $90 \mathrm{sec}$. The dogs were randomized into 3 groups after RM, i.e., Blip group, BiPAP $\mathrm{P}_{\text {low }}=\mathrm{LIP}+2 \mathrm{~cm} \mathrm{H} \mathrm{H}_{2} \mathrm{O}$; Bpmc group, BiPAP $\mathrm{P}_{\text {low }}=\mathrm{PMC}$; and Apmc group. In the APRV group, $\mathrm{P}_{\text {high }}$ was set as PMC, with an inspiratory duration of $4 \mathrm{sec}$ and expiratory duration of $0.4 \mathrm{sec}$. PMC was $18 \pm 1.4 \mathrm{~cm} \mathrm{H}_{2} \mathrm{O}$, and LIP was $11 \pm 1.3 \mathrm{~cm}$ $\mathrm{H}_{2} \mathrm{O}$. Thirty seconds after RM was stabilized, it was set as $0 \mathrm{~h}$. Hemodynamics, oxygenation and $\mathrm{DO}_{2}$ were measured at $0,1,2$ and $4 \mathrm{~h}$ after RM in ARDS dogs. The results demonstrated: i) cardiac index (CI) in the 3 groups, where CI was significantly decreased in the Bpmc group at $0,1,2$ and $4 \mathrm{~h}$
\end{abstract}

Correspondence to: Dr Jing-Yu Chen, Department of Lung Transplant Center, Wuxi People's Hospital Affiliated to Nanjing Medical University, 299 Qingyang Road, Wuxi, Jiangsu 214002, P.R. China

E-mail: bz124m@163.com

Key words: acute respiratory distress syndrome, airway pressure release ventilation, lung recruitment maneuver, canine, oxygen delivery after $\mathrm{RM}$ compared to prior to $\mathrm{RM}(\mathrm{P}<0.05)$ as well as in the Blip and Apmc groups $(\mathrm{P}<0.05)$. CI in the Blip and Apmc groups was not significantly altered prior to and after RM. ii) Oxygenation at $0,1,2$ and $4 \mathrm{~h}$ in the 3 groups was improved after RM and the oxygenation indices for the 3 groups at 1 and $2 \mathrm{~h}$ were not significantly different $(\mathrm{P}>0.05)$. However, the oxygenation index in the Blip group at $4 \mathrm{~h}$ was significantly lower than those at $0 \mathrm{~h}$ for the Apmc and Bpmc groups $(\mathrm{P}<0.05)$. Oxygenation for the Apmc group at $4 \mathrm{~h}$ was higher than that for the Blip and Bpmc groups $(\mathrm{P}<0.05)$. Oxygenation for the Bpmc group was lower than that at $0 \mathrm{~h}$, although the difference was not significant $(\mathrm{P}>0.05)$. iii) $\mathrm{DO}_{2}$ in at 0,1 , 2 and $4 \mathrm{~h}$ in the Bpmc group was significantly lower than that in the Blip and Apmc groups, and not significantly improved after RM. $\mathrm{DO}_{2}$ in the Blip and Apmc groups after RM was improved as compard to that before RM and that in the Bpmc group. However, $\mathrm{DO}_{2}$ at $4 \mathrm{~h}$ in the Blip group was significantly lower than that at $0 \mathrm{~h}$ and in the Apme group $(\mathrm{P}<0.05)$. $\mathrm{DO}_{2}$ at $4 \mathrm{~h}$ in the Apmc group was higher than that at $0 \mathrm{~h}$ and that in the remaining 2 groups $(\mathrm{P}<0.05)$. In conclusion, high APRV pressure guided at PMC of PV curve after RM significantly improved $\mathrm{DO}_{2}$ in ARDS dogs.

\section{Introduction}

The role of positive end-expiratory pressure (PEEP) guided by lower inflection point (LIP) in the pressure-volume (PV) curve after recruitment maneuver (RM) in severe acute respiratory distress syndrome (ARDS) to maintain expiratory end alveolar recruitment is controversial. LIP may reflect the open pressure of most alveoli at the inhalation phase, rather than alveolar closure pressure at exhalation (1).

It was previously reported that alveolar recruitment occurs above the inspiratory inflection point and PEEP $=\mathrm{LIP}+2-3 \mathrm{~cm}$ $\mathrm{H}_{2} \mathrm{O}$ did not maintain alveolar recruitment (1-3). Point of maximum curvature (PMC) pressure in the PV curve indicated the initiation of alveolar closure in exhalation. Previous studies suggested that PEEP guided by PMC was reasonable and significantly higher than that guided by LIP, leading to 
significant unfavorable impact on ventilation and blood flow as well as a higher risk of ventilator-induced lung injury (VILI) (4-6). Airway pressure release ventilation (APRV) involved the modification of continuous positive airway pressure (CPAP), and had been proven to decrease mean arterial pressure (MAP), as well as improve hemodynamics and alveolar collapse and prevent barotrauma (7-9).

Therefore, in the present study, we established a canine model of severe ARDS, and set high APRV pressure guided by PMC after RM, in order to maintain stable hemodynamics and alveolar recruitment, and improve oxygen delivery $\left(\mathrm{DO}_{2}\right)$.

\section{Materials and methods}

Animal model. In total, 18 healthy dogs (8 male and 10 female) were provided by the Laboratory Animal Center of Xuzhou Medical College (Jiangsu, China; non-SPF). Tracheotomy was performed after anesthesia, and intubation of trachea cannula (diameter $7.5 \mathrm{~mm}$ ). Volume control ventilation was performed, as well as tidal volume $\left(\mathrm{V}_{\mathrm{T}}\right) 6 \mathrm{ml} / \mathrm{kg}$, breath rate 30 times $/ \mathrm{min}$, inspiration duration of $0.8 \mathrm{sec}$, inspiratory pause of $0.1 \mathrm{sec}$, fraction of inspired oxygen $\left(\mathrm{FiO}_{2}\right) 80 \%$, and PEEP $5 \mathrm{~cm} \mathrm{H}$ $\left(1 \mathrm{~cm} \mathrm{H} \mathrm{H}_{2} \mathrm{O}=0.098 \mathrm{kPa}\right)$.

Deep venous catheter was intubated in the right internal jugular vein and connected with a pulse contour cardiac output (PiCCO) instrument (Pulsion Medical Systems SE, Munich, Germany) through a temperature detector. PiCCO arterial canal (Pulsion Medical Systems SE) was intubated in the right femoral artery. For the ARDS model, $0.2 \mathrm{ml} / \mathrm{kg}$ oleic acid was mixed with an equal volume of autologous blood and pumped into vein. Arterial blood was collected for blood gas analysis every $30 \mathrm{~min}$. The dogs with oxygenation index [partial pressure of oxygen in arterial blood $\left.\left(\mathrm{PaO}_{2}\right) / \mathrm{FiO}_{2}\right] \leq 100 \mathrm{mmHg}$ for 30 min constituted a successful animal model and was included in the study (10).

The dogs received continuous intravenous injection of 1-2 $\mathrm{mg} \mathrm{x} \mathrm{kg}^{-1} \mathrm{x} \mathrm{h}^{-1}$ pentobarbital sodium for sedation. During the experiment, infusion was performed to maintain MAP $80 \mathrm{mmHg}(1 \mathrm{mmHg}=0.133 \mathrm{kPa})$ and central venous pressure (CVP) $>5 \mathrm{~cm} \mathrm{H}_{2} \mathrm{O}$ before RM.

The present study was approved by the ethics committee of Xuzhou Medical College.

PV curve and lung RM. After the animal model became stable, a static PV curve was plotted using a super-syringe technique, with $\mathrm{LIP}=18 \pm 1.4 \mathrm{~cm} \mathrm{H}_{2} \mathrm{O}$, and $\mathrm{PMC}=11 \pm 1.3 \mathrm{~cm}$ $\mathrm{H}_{2} \mathrm{O}$ (5). RM was performed after hemodynamics became stable. Respiratory mode was biphasic-positive airway pressure (BiPAP), $\mathrm{P}_{\text {high }}=40 \mathrm{~cm} \mathrm{H_{2 }} \mathrm{O}, \mathrm{P}_{\text {high }}=25 \mathrm{~cm} \mathrm{H} \mathrm{H}_{2} \mathrm{O}$, with an inspiration to expiration ratio of 1:2, while $\mathrm{P}_{\text {high }}$ was altered to $30 \mathrm{~cm} \mathrm{H}_{2} \mathrm{O}$ after $90 \mathrm{sec}(11)$.

Experimental groups. The dogs were randomized into 3 groups after RM: Blip group, $\mathrm{P}_{\text {low }}=\mathrm{LIP}+2 \mathrm{~cm} \mathrm{H}_{2} \mathrm{O}$; Bpmc group, $\mathrm{P}_{\text {low }}=\mathrm{PMC}$; Apmc group, $\mathrm{P}_{\text {low }}=\mathrm{PMC}$. In the APRV group, $\mathrm{P}_{\text {high }}$ was set as $\mathrm{PMC}$, with an inspiratory duration of $4 \mathrm{sec}$, expiratory durationof $0.4 \mathrm{sec}$, and $\mathrm{P}_{\text {low }} 10 \mathrm{~cm} \mathrm{H}_{2} \mathrm{O}$.

Measurements. Thirty seconds after RM became stable, it was set as $0 \mathrm{~h}$. The changes of hemodynamics, oxygenation

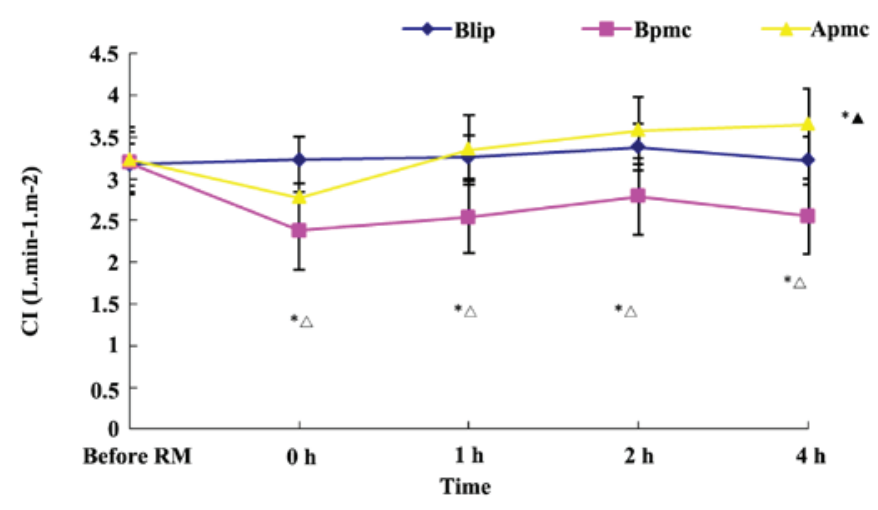

Figure 1. Effect of APRV on CI $\left(1 \times \mathrm{min}^{-1} \mathrm{x} \mathrm{m}^{-2}\right)$ after RM. In comparison to before $\mathrm{RM},{ }^{*} \mathrm{P}<0.05$; inter-group comparison, ${ }^{\wedge} \mathrm{P}<0.05$; in comparison to $0 \mathrm{~h},{ }^{\wedge} \mathrm{P}<0.05$. APRV, airway pressure release ventilation; CI, cardiac index; $\mathrm{RM}$, recruitment maneuver.

and $\mathrm{DO}_{2}$ were observed at $0,1,2$ and $4 \mathrm{~h}$ after RM in ARDS dogs. Hemodynamics measurements included heart rate (HR), MAP, cardiac index (CI) and CVP. Additionally, blood gas analysis was $\mathrm{PaO}_{2}$ for calculation of the oxygenation index. $\mathrm{DO}_{2}$ involved $\mathrm{DO}_{2}=10 \times \mathrm{CI} \times$ arterial oxygen content $\left(\mathrm{CaO}_{2}\right)$, and $\mathrm{CaO}_{2}=1.34 \mathrm{x}$ blood oxygen saturation $\left(\mathrm{SaO}_{2}\right) \times \mathrm{Hb}+0.003 \times \mathrm{PaO}_{2}$.

Statistical analysis. SPSS 13.0 software (Chicago, IL, USA) was used for statistical analysis. Data were presented as mean \pm SD. Analysis of variance was used for inter-group comparison. $\mathrm{P}<0.05$ indicated statistically significant results.

\section{Results}

General. Hemothorax and pulmonary edema were identified in specimens of ARDS dogs. Furthermore, hemorrhage in the region of proximal spine was evident although there was no pneumothorax.

There was no significant difference in the MAP, CI and $\mathrm{Hb}$ between ARDS dogs when compared to before model establishment $(\mathrm{P}>0.05)$ (Table I). For $\mathrm{PaO}_{2} / \mathrm{FiO}_{2}$ and static lung compliance there was a significant decrease observed following establishment of the ARDS model when compared to values prior to model $(\mathrm{P}<0.05)$. However, the differences between the 3 groups were not statistically significant $(\mathrm{P}>0.05)$.

Hemodynamics. CI in the Bpmc group at $0,1,2$ and $4 \mathrm{~h}$ was significantly lower than that before RM $(\mathrm{P}<0.05)$, and in the Blip and Apmc groups $(\mathrm{P}<0.05)$. CI in Blip group at 0,1 , 2 and $4 \mathrm{~h}$ was not significantly different from that before RM. $\mathrm{CI}$ in the Apmc group at $\mathrm{O} \mathrm{h}$ was decreased, although the difference was not significant, and CI gradually increased (Fig. 1).

$\mathrm{HR}$ in the Bpmc group was significantly increased compared to that before RM and also when compared to the Blip and Apmc groups $(\mathrm{P}<0.05)$, whereas HR in the Blip and Apmc groups was not significantly altered $(\mathrm{P}>0.05)$. MAP in the Bpmc group was significantly lower compared to that before RM and also when compared to the Blip and Apmc groups $(\mathrm{P}<0.05)$, whereas MAP in the Blip and Apmc groups was not significantly altered $(\mathrm{P}>0.05)$ (Tables II and III). 
Table I. Measurements at baseline and in the ARDS models.

\begin{tabular}{|c|c|c|c|c|}
\hline Item/group & Baseline & ARDS & $\mathrm{t}$ & P-value \\
\hline \multicolumn{5}{|c|}{ MAP (mmHg) } \\
\hline Blip & $144.2 \pm 8.9$ & $104.8 \pm 8.2$ & 7.317 & 0.000 \\
\hline Bpmc & $136.8 \pm 5.6$ & $103.6 \pm 6.6$ & 8.620 & 0.000 \\
\hline Apmc & $137.8 \pm 6.5$ & $105.8 \pm 10.3$ & 5.905 & 0.000 \\
\hline $\mathrm{F}$ & 0.311 & 0.551 & - & - \\
\hline P-value & 0.739 & 0.652 & - & - \\
\hline \multicolumn{5}{|c|}{$\mathrm{CI}\left(\mathrm{l} / \mathrm{min} / \mathrm{cm}^{2}\right)$} \\
\hline Blip & $4.3 \pm 0.7$ & $2.6 \pm 0.4$ & 4.739 & 0.000 \\
\hline Bpmc & $3.4 \pm 0.3$ & $2.5 \pm 0.4$ & 4.047 & 0.001 \\
\hline Apmc & $4.7 \pm 0.6$ & $2.5 \pm 0.4$ & 6.856 & 0.000 \\
\hline $\mathrm{F}$ & 2.409 & 0.181 & - & - \\
\hline P-value & 0.132 & 0.834 & - & - \\
\hline \multicolumn{5}{|l|}{$\mathrm{Hb}(\mathrm{g} / \mathrm{l})$} \\
\hline Blip & $142 \pm 12$ & $140 \pm 14$ & 0.244 & 0.847 \\
\hline Bpmc & $148 \pm 12$ & $136 \pm 15$ & 1.404 & 0.155 \\
\hline Apmc & $144 \pm 14$ & $138 \pm 15$ & 0.632 & 0.557 \\
\hline $\mathrm{F}$ & 1.067 & 1.313 & - & - \\
\hline P-value & 0.444 & 0.305 & - & - \\
\hline \multicolumn{5}{|c|}{ Static lung compliance $\left(\mathrm{ml} / \mathrm{cm} \mathrm{H}_{2} \mathrm{O}\right)$} \\
\hline Blip & $31.3 \pm 1.6$ & $13.9 \pm 0.8^{\mathrm{a}}$ & 4.888 & 0.000 \\
\hline Bpmc & $34.3 \pm 1.1$ & $14.9 \pm 0.8^{\mathrm{a}}$ & 24.37 & 0.000 \\
\hline Apmc & $32.7 \pm 2.1$ & $14.7 \pm 0.8^{\mathrm{a}}$ & 18.01 & 0.000 \\
\hline $\mathrm{F}$ & 0.946 & 1.410 & - & - \\
\hline P-value & 0.418 & 0.29 & - & - \\
\hline \multicolumn{5}{|c|}{$\mathrm{PaO}_{2} / \mathrm{FiO}_{2}(\mathrm{mmHg})$} \\
\hline Blip & $398 \pm 10$ & $90 \pm 12^{\mathrm{a}}$ & 44.31 & 0.000 \\
\hline Bpmc & $424 \pm 13$ & $92 \pm 9^{\mathrm{a}}$ & 47.184 & 0.000 \\
\hline Apmc & $414 \pm 15$ & $92 \pm 10^{\mathrm{a}}$ & 40.14 & 0.000 \\
\hline $\mathrm{F}$ & 1.044 & 1.073 & - & - \\
\hline P-value & 0.382 & 0.326 & - & - \\
\hline
\end{tabular}

In comparison to baseline, ${ }^{\mathrm{a}} \mathrm{P}<0.05$. ARDS, acute respiratory distress syndrome; $\mathrm{MAP}$, mean arterial pressure; $\mathrm{CI}, \mathrm{cardiac}$ index; $\mathrm{PaO}{ }_{2}, \mathrm{partial}$ pressure of oxygen in arterial blood; $\mathrm{FiO}_{2}$, fraction of inspired oxygen.

Table II. Effect of APRV on MAP (mmHg) after RM.

\begin{tabular}{|c|c|c|c|c|c|c|c|}
\hline Group & Before RM & $0 \mathrm{~h}$ & $1 \mathrm{~h}$ & $2 \mathrm{~h}$ & $4 \mathrm{~h}$ & $\mathrm{~F}$ & P-value \\
\hline Blip & $116 \pm 14$ & $107 \pm 12$ & $109 \pm 13$ & $109 \pm 15$ & $114 \pm 12$ & 0.806 & 0.453 \\
\hline Bpmc & $114 \pm 15$ & $90 \pm 12^{\mathrm{a}, \mathrm{b}}$ & $91 \pm 13^{a, b}$ & $92 \pm 14^{\mathrm{a}, \mathrm{b}}$ & $92 \pm 11^{\mathrm{a}, \mathrm{b}}$ & 11.942 & 0.001 \\
\hline Apmc & $114 \pm 14$ & $104 \pm 12$ & $102 \pm 13$ & $103 \pm 11$ & $106 \pm 14$ & 1.395 & 0.243 \\
\hline $\mathrm{F}$ & 0.045 & 8.803 & 8.823 & 8.369 & 8.419 & - & - \\
\hline P-value & 0.956 & 0.021 & 0.021 & 0.026 & 0.023 & - & - \\
\hline
\end{tabular}

In comparison to before $\mathrm{RM},{ }^{\mathrm{a}} \mathrm{P}<0.05$; inter-group comparison, ${ }^{\mathrm{b}} \mathrm{P}<0.05$. APRV, airway pressure release ventilation; MAP, mean arterial pressure; RM, recruitment maneuver.

Blood gas analysis. Oxygenation in the 3 groups after RM was improved compared to before RM (Fig. 2). Comparisons between the groups showed that the oxygenation index in the
3 groups at 1 and $2 \mathrm{~h}$ was not significantly different than at $0 \mathrm{~h}(\mathrm{P}>0.05)$. The oxygenation index at $0 \mathrm{~h}$ in the Blip group was significantly lower than that in the Apmc and 
Table III. Effect of APRV on HR (beat/min) after RM.

\begin{tabular}{lcccccc}
\hline Group & Before RM & $0 \mathrm{~h}$ & $1 \mathrm{~h}$ & $2 \mathrm{~h}$ & $4 \mathrm{~h}$ & $\mathrm{~F}$ \\
\hline Blip & $106 \pm 14$ & $102 \pm 8$ & $103 \pm 12$ & $102 \pm 15$ & $104 \pm 12$ & 0.803 \\
Bpmc & $104 \pm 15$ & $125 \pm 9^{\mathrm{a}, \mathrm{b}}$ & $124 \pm 12^{\mathrm{a}, \mathrm{b}}$ & $122 \pm 14^{\mathrm{a}, \mathrm{b}}$ & $122 \pm 13^{\mathrm{a}, \mathrm{b}}$ & 10.256 \\
Apmc & $104 \pm 14$ & $114 \pm 14$ & $100 \pm 14$ & $98 \pm 13$ & $96 \pm 14$ & 1.369 \\
F & 0.045 & 6.803 & 6.823 & 6.369 & 6.419 & 0.017 \\
P-value & 0.956 & 0.034 & 0.032 & 0.038 & 0.036 & - \\
\hline
\end{tabular}

In comparison to before $\mathrm{RM},{ }^{\mathrm{a}} \mathrm{P}<0.05$; inter-group comparison, ${ }^{\mathrm{b}} \mathrm{P}<0.05$. APRV, airway pressure release ventilation; HR, heart rate; $\mathrm{RM}$, recruitment maneuver.

Table IV. Effect of APRV on $\mathrm{PaCO}_{2}(\mathrm{mmHg})$ after RM.

\begin{tabular}{|c|c|c|c|c|c|c|c|}
\hline Group & Before RM & $0 \mathrm{~h}$ & $1 \mathrm{~h}$ & $2 \mathrm{~h}$ & $4 \mathrm{~h}$ & $\mathrm{~F}$ & $\mathrm{P}$-value \\
\hline Blip & $35 \pm 9$ & $37 \pm 7$ & $43 \pm 8$ & $42 \pm 7$ & $35 \pm 7$ & 0.923 & 0.876 \\
\hline Bpmc & $32 \pm 7$ & $37 \pm 9$ & $47 \pm 9^{a}$ & $51 \pm 8^{a, b}$ & $53 \pm 13^{\mathrm{a}, \mathrm{b}}$ & 16.103 & 0.000 \\
\hline Apmc & $33 \pm 9$ & $36 \pm 8$ & $39 \pm 8$ & $43 \pm 7$ & $42 \pm 7$ & 2.494 & 0.342 \\
\hline $\mathrm{F}$ & 0.666 & 0.708 & 1.554 & 3.421 & 6.788 & - & - \\
\hline P-value & 0.519 & 0.471 & 0.316 & 0.218 & 0.036 & - & - \\
\hline
\end{tabular}

In comparison to before $\mathrm{RM}$, ${ }_{\mathrm{P}}^{\mathrm{P}}<0.05$; inter-group comparison, ${ }^{\mathrm{b}} \mathrm{P}<0.05$. $\mathrm{APRV}$, airway pressure release ventilation; $\mathrm{PaCO}_{2}$, partial pressure of oxygen in arterial blood; RM, recruitment maneuver.

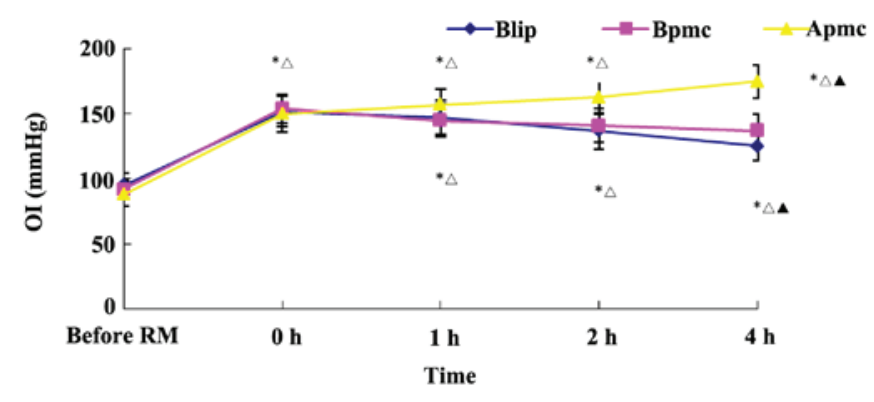

Figure 2. Effect of APRV on $\mathrm{PO}_{2} / \mathrm{FiO}_{2}(\mathrm{mmHg})$ after RM. In comparison to before $\mathrm{RM},{ }^{*} \mathrm{P}<0.05$; inter-group comparison, ${ }^{\triangle} \mathrm{P}<0.05$; in comparison to $0 \mathrm{~h},{ }^{\wedge} \mathrm{P}<0.05$. APRV, airway pressure release ventilation; $\mathrm{FiO}_{2}$, fraction of inspired oxygen RM, recruitment maneuver.

Bpmc groups $(\mathrm{P}<0.05)$. The oxygenation index at $0 \mathrm{~h}$ in Apmc group was higher than that in Blip and Bpmc groups $(\mathrm{P}<0.05)$. As shown in Table IV, $\mathrm{PaO}_{2}$ after $\mathrm{RM}$ in $\mathrm{Bpmc}$ group was gradually increased $(\mathrm{P}<0.05)$, while $\mathrm{PaO}_{2}$ after $\mathrm{RM}$ in Blip and Apmc groups was not significantly increased $(\mathrm{P}>0.05)$.

$\mathrm{DO}_{2}$. Alteration of the $\mathrm{DO}_{2}$ ratio $\left(\mathrm{DO}_{2}\right.$ after $\mathrm{RM} / \mathrm{DO}_{2}$ before $\mathrm{RM}$ ) reflected $\mathrm{DO}_{2}$ in different groups. $\mathrm{DO}_{2}$ in the Bpmc group at 0,1 , and $4 \mathrm{~h}$ was significantly lower than that in the Blip and Apmc groups, and not significantly improved compared to before RM (Fig. 3). $\mathrm{DO}_{2}$ in the Blip and Apmc groups after RM was improved compared to that before RM and in the Bpmc group. However, $\mathrm{DO}_{2}$ at $4 \mathrm{~h}$ in the Blip group was significantly lower than that at $0 \mathrm{~h}$ and in the Apmc group $(\mathrm{P}<0.05) . \mathrm{DO}_{2}$ at

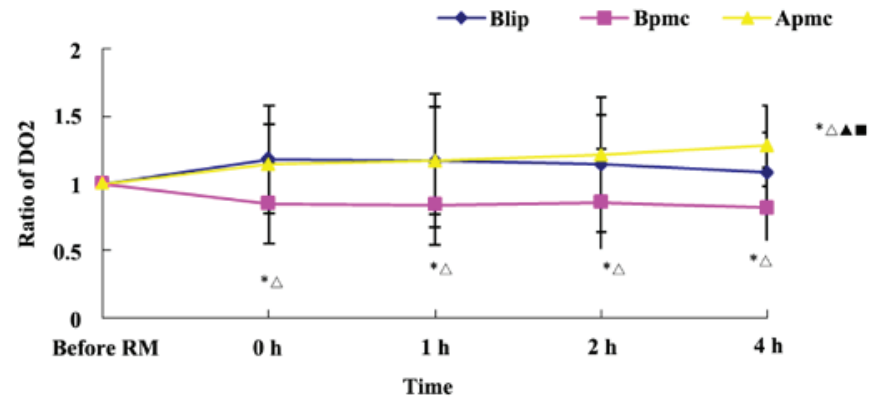

Figure 3. Effect of APRV on $\mathrm{DO}_{2}$ after RM. In comparison to before RM, ${ }^{*} \mathrm{P}<0.05$; inter-group comparison, ${ }^{\triangle} \mathrm{P}<0.05$; in comparison to $0 \mathrm{~h},{ }^{\wedge} \mathrm{P}<0.05$; in comparison to the Blip group, $" \mathrm{P}<0.05$. APRV, airway pressure release ventilation; $\mathrm{DO}_{2}$, oxygen delivery $\mathrm{RM}$, recruitment maneuver.

$4 \mathrm{~h}$ in the Apmc group was higher than that at $0 \mathrm{~h}$, in the Blip and Bpmc groups $(\mathrm{P}<0.05)$.

\section{Discussion}

PEEP guided by LIP in the open lung approach after RM in severe ARDS is a controversial intervention (1). Severe ARDS required $\mathrm{RM}$ to open collapsed alveoli, especially for extra pulmonary ARDS. RM increased lung volume, and improved oxygenation and lung compliance. However, PEEP was set to maintain open alveoli and prevent the re-collapse of alveoli after the open lung approach $(1,12,13)$. Currently, most studies demonstrated that PEEP could be guided by LIP in PV curve, $\mathrm{PEEP}=\mathrm{LIP}+2-3 \mathrm{~cm} \mathrm{H}_{2} \mathrm{O}$. LIP represented the transition component from low to high compliance in the inspiratory $\mathrm{PV}$ 
curve, i.e., the pressure on recruitment of most alveoli. It was reported that the point of maximum compliance in the inspiratory PV curve was able to reflect alveolar closure pressure indirectly. PEEP guided by LIP had the following limitations: i) maximum compliance represented by LIP in inhale branch indicated recruitment in most alveoli rather than end-exhale closure; ii) PV curve in ARDS did not necessarily have LIP; and iii) alveolar recruitment may occur above the high inflection point of inhale branch. PEEP=LIP+2-3 $\mathrm{cm} \mathrm{H}_{2} \mathrm{O}$ did not maintain alveolar recruitment (14) and lung recruitment sufficiently (1-3). In the present study, oxygenation in the Blip group was significantly decreased $4 \mathrm{~h}$ after RM in comparison to $2 \mathrm{~h}$, indicating that the collapse of some recruited alveoli at $4 \mathrm{~h}$ after RM, leading to decreased oxygenation and $\mathrm{DO}_{2}$.

PEEP guided by PMC was reasonable in theory. PMC in the PV curve indicated the initiation of alveolar closure in the exhale phase, i.e., with airway pressure decreasing, many alveoli collapsed rapidly. PEEP set at this point may prevent alveolar collapse in the exhale phase. However, PEEP guided by PMC was significantly higher than that guided by LIP, leading to a more unfavorable impact on ventilation and blood flow (15) as well as a higher risk of VILI. Therefore, it was not applied $(16,17)$. Crotti et al rescued one ARDS patient with septicemia by RM, PEEP $25 \mathrm{~cm} \mathrm{H}_{2} \mathrm{O}$, LIP $16-18 \mathrm{~cm}$ $\mathrm{H}_{2} \mathrm{O}$ (18). $\mathrm{Xu}$ et al showed that PEEP guided by PMC may improve oxygenation and shunt significantly, however, CI and even $\mathrm{DO}_{2}$ were decreased (5). In the present study, hemodynamics in the Bpmc group was unstable, CI and MAP were decreased, and oxygenation at $4 \mathrm{~h}$ after RM was decreased, although these differences were not significant. Additionally, $\mathrm{DO}_{2}$ at $0,1,2$ and $4 \mathrm{~h}$ was significantly decreased. Therefore, in the case of PEEP simply guided by PMC, unstable hemodynamics should be monitored to maintain $\mathrm{DO}_{2}$ and prevent increased $\mathrm{PCO}_{2}$ or barotrauma.

APRV may recruit collapsed lung tissue, maintain maximum and persistent alveolar recruitment as well as hemodynamics. APRV is a modification of CPAP (7). The addition of the pressure-relief valve in exhale branch allowed pressure control, time trigger, pressure limit and time switch, and spontaneous breath in the respiratory cycle (7). High pressure maintained alveolar recruitment while low pressure facilitated expelling $\mathrm{CO}_{2}$ and maintained open alveoli of diffusion constant. Although MAP was increased, peak airway pressure was decreased in order to expel $\mathrm{CO}_{2}$ and reduce barotrauma. Transient pressure relief may decrease intrathoracic pressure and promote right cardiac venous return. Spontaneous breath was not only able to reduce sedative dose, but also the pressure to intrathoracic heart and great vessels by increased airway pressure. This may promote venous return, increase $\mathrm{CO}_{2}$ and $\mathrm{DO}_{2}$, and improve organ perfusion (19).

In the present study, high APRV pressure in the Apmc group was guided by PMC to avoid alveolar collapse and maintain open lung, and further improve oxygenation; thus, oxygenation at $4 \mathrm{~h}$ after RM was improved. Additionally, the circulation became stable to improve $\mathrm{DO}_{2}$. It was also able to expel $\mathrm{CO}_{2}$ without increasing peak airway pressure.

In conclusion, high APRV pressure guided by PMC further opened lung, improved oxygenation significantly, maintained stable hemodynamics and improved $\mathrm{DO}_{2}$.

\section{References}

1. Richard JC, Maggiore SM, Jonson B, Mancebo J, Lemaire F and Brochard L: Influence of tidal volume on alveolar recruitment. Respective role of PEEP and a recruitment maneuver. Am J Respir Crit Care Med 163: 1609-1613, 2001.

2. Cakar N, der Kloot TV, Youngblood M, Adams A and Nahum A: Oxygenation response to a recruitment maneuver during supine and prone positions in an oleic acid-induced lung injury model. Am J Respir Crit Care Med 161: 1949-1956, 2000.

3. Grasso S, Mascia L, Del Turco M, Malacarne P, Giunta F, Brochard L, Slutsky AS and Marco Ranieri V: Effects of recruiting maneuvers in patients with acute respiratory distress syndrome ventilated with protective ventilatory strategy. Anesthesiology 96: 795-802, 2002.

4. Hickling KG: Reinterpreting the pressure-volume curve in patients with acute respiratory distress syndrome. Curr Opin Crit Care 8: 32-38, 2002.

5. Xu Y, Lei Z and Niu S: Respiratory pressure-volume curve in open lung strategy in dog with acute respiratory distress syndrome. Chin J Respir Crit Monit 3: 198-203, 2006 (In Chinese).

6. Gang L, Sun XY, Xu JQ, Zhang XL, Kou LX, Jiang ZH and Zhang L: A comparative study between inflation and deflation pressure-volume curve in determining the optimal positive end-expiratory pressure. Zhongguo Wei Zhong Bing Ji Jiu Yi Xue 24: 74-77, 2012 (In Chinese).

7. Demirkol D, Karabocuoglu M and Citak A: Airway pressure release ventilation: an alternative ventilation mode for pediatric acute hypoxemic respiratory failure. Indian J Pediatr 77: 1322-1325, 2010.

8. Kallet RH: Patient-ventilator interaction during acute lung injury, and the role of spontaneous breathing: part 2: airway pressure release ventilation. Respir Care 56: 190-203, discussion 203-206, 2011.

9. Hamdy HA, Gaber R and Gehan HA: Study of cardiac and hemodynamic changes with airway pressure release ventilation and pressure control ventilation in children with acute respiratory distress syndrome. Eur Respir J 40: 4639, 2012.

10. Grasso S, Terragni P, Mascia L, Fanelli V, Quintel M, Herrmann P, Hedenstierna G, Slutsky AS and Ranieri VM: Airway pressure-time curve profile (stress index) detects tidal recruitment/hyperinflation in experimental acute lung injury. Crit Care Med 32: 1018-1027, 2004.

11. Lim SC, Adams AB, Simonson DA, Dries DJ, Broccard AF, Hotchkiss JR and Marini JJ: Intercomparison of recruitment maneuver efficacy in three models of acute lung injury. Crit Care Med 32: 2371-2377, 2004.

12. Frank JA, McAuley DF, Gutierrez JA, Daniel BM, Dobbs L and Matthay MA: Differential effects of sustained inflation recruitment maneuvers on alveolar epithelial and lung endothelial injury. Crit Care Med 33: 181-188, discussion 254-255, 2005.

13. Hartland BL, Newell TJ and Damico N: Alveolar recruitment maneuvers under general anesthesia: a systematic review of the literature. Respir Care 60: 609-620, 2015.

14. Xu L, Wang SP, Zhang NX and Qin YZ: Effects of different levels of positive end expiratory pressure on lung recruitment and hemodynamics after sustained inflation in acute respiratory distress syndrome in sheep. Zhongguo Wei Zhong Bing Ji Jiu Yi Xue 17: 679-682, 2005 (In Chinese).

15. Qiu HB, Xu HY, Yang Y, Zhou SX, Chen YM and Sun HM: Effects of positive end-expiratory pressure on lung recruited volume and oxygenation in patients with acute respiratory distress syndrome. Zhongguo Wei Zhong Bing Ji Jiu Yi Xue 16: 399-402, 2004 (In Chinese).

16. Pintado MC, de Pablo R, Trascasa M, Milicua JM, Rogero S, Daguerre M, Cambronero JA, Arribas I and Sánchez-García M: Individualized PEEP setting in subjects with ARDS: arandomized controlled pilot study. Respir Care 58: 1416-1423, 2013.

17. Spieth PM and Gama de Abreu M: Lung recruitment in ARDS: We are still confused, but on a higher PEEP level. Crit Care 16: 108, 2012

18. Crotti S, Mascheroni D, Caironi P, Pelosi P, Ronzoni G, Mondino M, Marini JJ and Gattinoni L: Recruitment and derecruitment during acute respiratory failure: a clinical study. Am J Respir Crit Care Med 164: 131-140, 2001.

19. Daoud EG, Farag HL and Chatburn RL: Airway pressure release ventilation: what do we know? Respir Care 57: 282-292, 2012. 